SANTANA, A.F., RESENDE, L.P. e CAETANO A.L.S. Avaliação do diagnóstico precoce de gestação através de exames citológicos do tecido epitélio vaginal, em ovelhas da raça Santa Inês. PUBVET, Londrina, V. 5, N. 33, Ed. 180, Art. 1215, 2011.

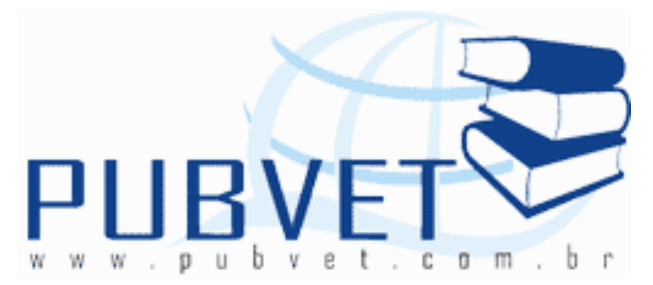

PUBVET, Publicações em Medicina Veterinária e Zootecnia.

\title{
Avaliação do diagnóstico precoce de gestação através de exames citológicos do tecido epitélio vaginal, em ovelhas da raça Santa Inês
}

\author{
Adelmo Ferreira de Santana ${ }^{1}$, Lívia Paola Resende ${ }^{2}$, Adriano Leão Silva
} Caetano ${ }^{1}$
${ }^{1}$ Médico Veterinário, Professor do Departamento de Produção Animal da Escola de Medicina Veterinária - UFBA.
${ }^{2}$ Estudante de graduação da Escola de Medicina Veterinária - UFBA

\section{Resumo}

O trabalho analisou as alterações citológicas do tecido epitélio vaginal de 40 ovelhas da raça Santa Inês, que através do exame, conduzissem ao diagnóstico de gestação. Foram escolhidas as ovelhas, aleatoriamente, o material foi coletado com o auxilio de um swab, em seguidas foram preparadas as lâminas e a coloração utilizada foi Papanicolau. Os animais gestantes apresentaram predominância das células parabasais (58,93\%), enquanto, que os animais não gestantes apresentaram predominância das células intermediárias (72,83\%).

Palavras-chave: Citologia, diagnóstico de prenhez, reprodução, ovinos (ovis aries). 
SANTANA, A.F., RESENDE, L.P. e CAETANO A.L.S. Avaliação do diagnóstico precoce de gestação através de exames citológicos do tecido epitélio vaginal, em ovelhas da raça Santa Inês. PUBVET, Londrina, V. 5, N. 33, Ed. 180, Art. 1215, 2011.

\section{Evaluation of early diagnosis of pregnancy through the fabric of cytological vaginal epithelium sheep Santa Ines}

\section{Summary}

The study investigated the different characteristics of the vaginal epithelium of 40 goat from Santa Inês, who through the examination, would lead to the diagnosis of pregnant or not pregnant. Ewes were chosen randomly collected material for analysis with the aid of a swab in a row were prepared slides, the Papanicolaou stain was used. The pregnant animals showed a predominance of parabasal cells (58.93\%), while non-pregnant animals showed a predominance of intermediate cells $(72.83 \%)$.

Keywords: cytology, diagnosis of pregnancy, reproduction, goat (Ovis Aries

\section{INTRODUÇÃO}

Na região nordeste a caprino-ovinocultura possui grande importância econômica e social, devido a capacidade dos animais de se adaptarem ao clima seco e a alimentação regional, sendo muitas vezes escassas, nesta região. A intervenção de técnicas laboratoriais citológicas na reprodução deste rebanho permite melhorias neste setor a fim de torná-lo mais eficiente. O resultado da eficiência do sistema produtivo seria de uma maior rentabilidade com a inserção em novos mercados e maior competitividade do setor. (CARVALHO e SOUZA, 2009).

Em decorrência às demandas produtivas, o diagnóstico de prenhez através da análise citológica e histológica do tecido epitelial da vagina desses animais é de grande importância para a confirmação da gestação e, em caso negativo, o aproveitamento do ciclo estral do animal. (SCHUTTEC, 1967)

Pois, durante o ciclo estral o tecido epitelial da vagina sofre várias alterações devido à ação dos hormônios esteróide E2 (Estradiol) e P4 (progesterona), ocorrendo o aparecimento de células epiteliais, em formas e 
SANTANA, A.F., RESENDE, L.P. e CAETANO A.L.S. Avaliação do diagnóstico precoce de gestação através de exames citológicos do tecido epitélio vaginal, em ovelhas da raça Santa Inês. PUBVET, Londrina, V. 5, N. 33, Ed. 180, Art. 1215, 2011.

números variados e, também, o aparecimento de leucócitos. (SCHUTTEC, 1967).

O ciclo estral é formado por períodos cíclicos e seqüenciais de proestro, estro, metaestro, diestro e anestro. O ciclo estro tem duração de aproximadamente 21 dias, sendo o proestro de 2 a 3 dias, estro varia de 30 a 40 horas, metaestro de 2 a 3 dias e diestro de 13 a 15 dias. Podendo ocorrer variação devido a fatores ambientais, climáticos e alimentares. (HULRET e SHELTON, 1998).

A análise da citologia vaginal utilizada pela medicina veterinária como diagnóstico de gestação em ovelhas é um método rápido, eficiente e econômico, podendo ser realizado através do esfregaço vaginal e preparação de lâminas para observação microscópica.

Existem vários métodos de coloração das células fixadas nas lâminas para análise das fases do ciclo estral, entre esses o Giemsa, Shorr, H-E (Hematoxilina de Harris e Eosina). O método de coloração utilizado neste trabalho foi o Papanicolaou

As células do tecido epitelial vaginal são classificadas em basais, parabasais, intermediárias, superficiais com núcleo e superficiais anucleadas. No tecido epitelial, as células basais se repousam sobre a membrana basal. Estas células são pequenas, possuem formato ovóide, com grande núcleo e, dificilmente são encontrados no esfregaço vaginal. (ETTINGER, 1992).

$\mathrm{Na}$ segunda camada do epitélio vaginal, encontram-se as células parabasais, as quais, apresentam o mesmo formato das células basais, com exceção do seu núcleo que é um pouco menor. As células intermediárias apresentam núcleo menor que as células parabasais e sua forma é navicular. As células superficiais se caracterizam de duas formas; com núcleos picnócitos e células anucleadas, possuem formato navicular e são maiores que as intermediárias. (ETTINGER, 1992) 
SANTANA, A.F., RESENDE, L.P. e CAETANO A.L.S. Avaliação do diagnóstico precoce de gestação através de exames citológicos do tecido epitélio vaginal, em ovelhas da raça Santa Inês. PUBVET, Londrina, V. 5, N. 33, Ed. 180, Art. 1215, 2011.

A citologia vaginal esfoliativa é um método de diagnóstico bastante confiável aos estudos da reprodução em cabras e ovelhas, em virtude de sua eficiência e rapidez no monitoramento reprodutivo dos animais. (VANNUCCHI et al., 1997).

O objetivo deste trabalho foi analisar as alterações citológicas no tecido epitelial vaginal através da técnica de coloração de células - Papanicolaou, em ovelhas. A fim de promover um melhor monitoramento no ciclo estral das fêmeas, aumentando, assim, a reprodução destes animais.

\section{MATERIAL E MÉTODOS}

Este trabalho foi realizado na Fazenda Experimental da Escola de Medicina Veterinária da Universidade Federal da Bahia (UFBA), localizada no município de Entre Rios, Bahia, Brasil. Localizado a uma latitude $11^{\circ} 56^{\prime} 31^{\prime \prime}$ sul, longitude de $38^{\circ} 05^{\prime} 04^{\prime \prime}$ oeste, está em uma altitude de 162 metros, possui clima úmido com temperatura média de $24^{\circ} \mathrm{C}$. No mês de abril de 2009.

Foram utilizadas quarenta ovelhas da raça Santa Inês, na fase de lactação, amamentação, vazia e prenha, para descrever o perfil citológico das ovelhas gestantes e não gestantes.

A coleta foi feita apenas uma vez em cada animal, através do swab vaginal, sendo em seguida confeccionado um esfregaço vaginal por coleta por ovelha, em lâminas de vidro, secados a temperatura ambiente e fixado em álcool a $95 \%$, por 5 minutos.

Os esfregaços vaginais obtidos foram corados pelo método de Papanicolau. As lâminas foram observadas ao microscópico óptico com aumentos de 400X para a visualização das características morfológicas e tintoriais das células epiteliais ao longo do ciclo estral. As células foram classificadas em quatro tipos: parabasais, intermediárias, superficiais nucleadas e superficiais anucleadas (ETTINGER, 1992). Os resultados foram 
SANTANA, A.F., RESENDE, L.P. e CAETANO A.L.S. Avaliação do diagnóstico precoce de gestação através de exames citológicos do tecido epitélio vaginal, em ovelhas da raça Santa Inês. PUBVET, Londrina, V. 5, N. 33, Ed. 180, Art. 1215, 2011.

expressos na forma de média e desvio-padrão. Os dados foram submetidos ao teste de Tukey $(p<0,05)$.

\section{RESULTADO E DISCUSSÃO}

Os resultados relativos ao percentual médio e desvio-padrão dos diferentes tipos de células epiteliais nas diferentes fases do ciclo estral estão apresentados na tabela 1

Tabela 1. Percentual dos tipos de células observadas em exames citológicos para os grupos gestantes e não gestantes.

\begin{tabular}{|l|l|l|l|}
\hline Grupos & Gestante & Não Gestante & Total \\
\hline Parabasais & $58,93 \%$ & $41,07 \%$ & 100 \\
\hline Intermediárias & $27,17 \%$ & $72,83 \%$ & 100 \\
\hline Superficial Nucleada & $42,31 \%$ & $57,69 \%$ & 100 \\
\hline Superficial Anucleada & $18,18 \%$ & $81,82 \%$ & 100 \\
\hline
\end{tabular}

Os vários tipos celulares do epitélio vaginal foram encontrados distribuídos no grupo de ovelhas gestantes e não gestantes. O perfil citológico obtido demonstrou a presença das células parabasais, intermediárias, superficiais nucleadas e superficiais anucleadas, como demonstra a tabela 1.

As células basais não foram encontradas nos esfregaços citológicos, o que está de acordo com TONIOLLO et al. (2005).

Em relação ás células parabasais, o grupo gestante apresentou predomínio $(58,93 \%)$, resultado semelhante foi encontrado por Yamanda e Kozicki (1998) (47\%). Segundo esses autores este dado é devido a ausência da ação do hormônio estrógeno, indicando o não desenvolvimento folicular ovariano.

Conforme a tabela 1, as ovelhas não gestantes apresentaram o número de células superficial anucleada superior dos demais tipos celulares, estes resultados estão de acordo com os encontrados por PORTO et. al. (2007).

Segundo Schutter (1967), o grande número de células superficiais anucleadas apresentadas no grupo de ovelhas não gestantes, é justificado pela 
SANTANA, A.F., RESENDE, L.P. e CAETANO A.L.S. Avaliação do diagnóstico precoce de gestação através de exames citológicos do tecido epitélio vaginal, em ovelhas da raça Santa Inês. PUBVET, Londrina, V. 5, N. 33, Ed. 180, Art. 1215, 2011.

influência do hormônio estrógeno sobre o epitélio vaginal, o qual provoca uma intensa descamação do tecido, favorecendo o aparecimento deste tipo de célula no esfregaço vaginal das ovelhas que estão no estro.

O número de células superficiais anucleadas encontradas no experimento com ovelhas não gestantes se assemelha com o resultado encontrado por Santos et. al.(1997), no trabalho realizado com cadelas no estro que encontrou mais de $90 \%$ desse tipo de célula.

As células intermediárias apresentou um percentual baixo $(27,17 \%)$ no grupo gestante e elevado nas ovelhas não gestantes, o que concorda com Raposo et.al., (1999), que pesquisou em cabras cíclicas, as células intermediárias mantiveram elevadas durante as quatro fases do ciclo.

\section{Conclusão}

Com base nos resultados obtidos, conclui-se que é possível diferenciar uma ovelha gestante de outra não gestante, através da citologia esfoliativa. A citologia vaginal é uma técnica que pode ser utilizada para viabilizar o controle reprodutivo e a determinação do estro para a inseminação artificial.

\section{Referência}

CARVALHO, Daniela Moreira; SOUZA, Jalmir Pinheiro de. Análises da cadeia produtiva da caprino-cultura em Garanhus. Disponível em: <www.sober.org.br/palestra/9/673.pdf.>Acesso em: 13/05/2009.

ETTINGER, S. T. Tratado de Medicina Interna Veterinária: Moléstia do Cão e do Gato. São Paulo: Ed: Manole, 1992. p.20.

HULRET, C.V. ; SHELTON, M. Ciclos Reprodutivos - Ovinos e Caprinos, In: HAFEZ, E. S.R. Reprodução Animal. São Paulo, Ed. Manole, 1998. p. 397-411.

PORTO, Rhiane Rodrigues Macedo, CALVACANTE, T.V., DIAS, F.E.F; ROCHA, J.M.N.; SOUZA, J.A.T. Perfil citológico vaginal de ovelhas da raça Santa Inês no acompanhamento do ciclo estral. Ciência Animal Brasileira. v.8, n.3, p.521-527, jul/set. 2007.

RAPOSO, Ramon da Silva; SILVA, L.D.M.; LÔBO, R. N. B.; FREITAS, V.J.F.; DIAS, F.E.F. Perfil citológico vaginal de cabras cíclicas da raça Saanen. Ciência Animal, v.9, n.2, p.75-79, 1999.

SANTOS, S. E. C.; CRUSCO, S. E.; VANNUCCHI, C. I.; SATZINGER, S. Técnica de citologia vaginal como método de diagnóstico da fase do ciclo estral em cadelas. Revista Clínica Veterinária. São Paulo, n.9, p.14-19, 1997. 
SCHUTTER, A. P. Canine vaginale cytology I: Technique and Cytological Morphology. Journal Small Practice. Grã-Bretanha, v.8, p. 301-306, 1967.

TONIOLLO, G.H; MONREAL, I.A.; LAURA, W.V.; SALAZAR e A. DELFINI. Citologia vaginal em cabras alpinas sincronizadas com CIDR E ECG. Arch. Zootec. n.54: p.635-638, 2005.

VANNUCCHI, C.I; SATZINGER S.; SANTOS, S.C. Técnica de citologia vaginal como método diagnóstico da fase do ciclo estral em cadelas. Clin. Vet., v.2, n.9, p. 14-19, 1997.

YAMANDA, Maria Luiza Assis; KOZICKI, Luiz Ernandes. Contribuição ao estudo de gestação em Capra hircus, através da histologia e citologia do epitélio vaginal. Braz. J. vet. Res. Anim. Sci. São Paulo, v.35, n.6, p.246-251, 1998. 